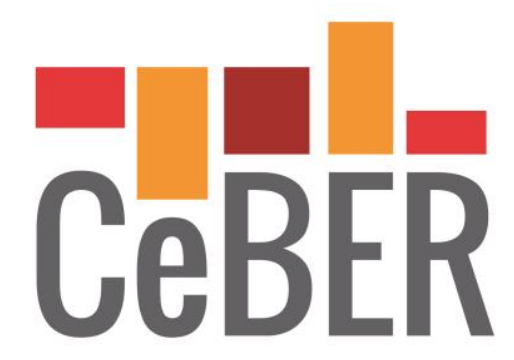

CENTRE FOR BUSINESS AND ECONOMICS RESEARCH

U UNIVERSITY OF COIMBRA

\title{
The Iberian electricity market: Price dynamics and risk premium in an illiquid market
}

\author{
MÁRCIO FERREIRA \\ CFisUC, Department of Physics, University of Coimbra
}

HÉLDER SEBASTIÃO

CeBER and Faculty of Economics of the University of Coimbra

\section{CeBER Working Papers}

No. 2 


\title{
The Iberian electricity market: Price dynamics and risk premium in an illiquid market
}

\author{
Márcio Ferreira * \\ CFisUC, Department of Physics, University of Coimbra, 3004-516 \\ Coimbra, Portugal \\ Helder Sebastião ${ }^{\dagger}$ \\ CeBER, Faculty of Economics, University of Coimbra, Portugal
}

May 12, 2018

\begin{abstract}
This paper studies the relationship between the electricity spot and futures prices in the Iberian electricity market, with a special focus on the ex-post risk premium of monthly futures contracts. The study covers the period from 1 July 2006 to 31 March 2017, during which 128 monthly futures contracts were traded. We show that the risk premium is dynamic and presents on average a negative value. Within contracts, the risk premium presents a non-linear dependence on the remaining trading days until maturity. There is no statistical evidence for rejecting the unbiased forward hypothesis of the futures prices. However, the sequence of futures prices near maturity has some predictive power on the risk premium.
\end{abstract}

\section{Introduction}

Nowadays, storing electricity is still financially infeasible. This non-storable characteristic of electricity is singular among most commodities. Therefore, sudden variations of electricity supply and/or demand cannot be accommodated via inventory management, implying that an equilibrium between supply and demand is required at every time. Hence, the efficiency of electricity markets is a challenging task, requiring additional balancing services and the management of reserve resources beyond the common production and distribution services.

\footnotetext{
*Electronic address: mferreira@teor.fis.uc.pt

$\dagger$ 'Electronic address: helderse@fe.uc.pt
} 
Recently, the electricity markets have experienced a worldwide deregulation trend, which led to the creation of new electricity spot and derivatives exchanges. The mechanisms of the price formation process in these exchanges have been subjected to close scrutiny from both academics and market participants and, most particularly, some attention has been paid to forward and futures risk premiums.

Several theoretical models have been proposed for the dynamics of the risk premium. The most known one is the equilibrium model in [1], which suggests that the risk premium depends on the market forecasts on the variance and asymmetry of electricity spot prices. Other models can be found in[2], [3] and [4]. The first paper proposes a mean-reverting jump diffusion process for the electricity spot price, while [3], assuming that the wholesale electricity prices are driven by demand and capacity, derive analytical expressions for the risk premium. In the same line of reasoning, [4] use a two-state price model on demand (load) and fuel price to study the risk premium.

Although using different procedures and studying different markets, the empirical evidence on the relationship between spot and futures electricity prices, and, particularly on the derivatives risk premium, is quite compelling. [5] show the existence of a risk premium in the futures prices on the New York Mercantile Exchange. The risk premium dynamics for the German electricity market is studied in [6], showing the existence of a term structure on the risk premium, originated by the interaction between risk aversion market agents. [7] presents evidence on the existence of a significant positive risk premium at the short-end for the electricity futures contracts for delivery in Germany traded at the European Energy Exchange (EEX). The impact of forward electricity prices and the relationship between forward and future spot prices is addressed in [8] for the EEX and the Nord Pool electricity markets. It is found that the spot prices skewness is significant for determining the base-load futures-spot bias at the EEX market, whereas the spot prices variance positively influences the risk premium in peak-load contracts. The risk premium in Nord Pool electricity market is also studied in [9], showing the existence of a dynamic risk premium, although positive on average. The risk premium in this market is also studied in[10], where a significant relationship is found between this risk premium and information on reservoir, inflow and electricity consumption. [11] revisited the previous work using GARCH errors, finding mainly a positive impact of water reservoir seasonal levels in the risk premium at the Nord Pool electricity market. [12] show that futures prices traded in the Amsterdam Power Exchange are not unbiased predictors of the future spots prices, which indicates the presence of a risk premium. The effect of fundamental, behavioral, dynamic, and shock components on electricity is analyzed in [13] for the EEX forward market. In the same line of reasoning, [14] apply a VAR model to distinguish between fundamental and behavioral determinants of prices and risk premiums in the British market. Using empirical enlargement filtration techniques, [15] find that a significant part of the risk premium in electricity forward contracts may be attributed to different information sets in spot and forward markets. The risk premium on month, quarter, and annual electricity forward contracts traded for the Nordic and German/Austrian is analyzed in [16]. Instead of an ex-post approach, the authors study the relationship between overnight returns and the risk premium. A positive average risk premium is found when producers hedge their production, becoming negative on average 
as large buyers enter the market. An empirical analysis on the Italian Market is carried out in [17], where the risk premium of monthly futures is evaluated.

The Iberian electricity market was studied in [18], [19], [20] and [21]. The first paper shows the existence of a linear dependence between ex-post risk premiums of the electricity markets of Germany, France and Spain. [19] confirm the existence of unidirectional causality from the futures to the forward and spot markets, suggesting that futures prices are used by market agents as a reference price. In [20], market efficiency is analysed for the Iberian futures markets and other European power markets. The study concludes for the presence of a risk premium in all markets and thus reject the hypothesis of market efficiency. In [21], the sign and magnitude of the risk premium is found to depend on both the unexpected variations in demand and in the hydroelectric capacity. The forward premium turned out to be negatively related to the variance of spot prices.

Our work contributes to the existing literature on the Iberian electricity market by examining thoroughly the dynamics of spot and futures prices, with a focus on the risk premium. Namely, we present its statistical properties, seasonal features, term structure and predictability using an up-to-date sample.

This paper is organized as follows. Section 2 gives a brief introduction to the basic structure of Iberian electricity market. The two futures pricing theories, namely the cost-of-carry and the hedging pressure theories, are introduced in Section 3. The data set is described in Section 4 and the results on the spot and futures price dynamics are presented in Section 5. Section 6 is dedicated to the study of the risk premium, namely the forward unbiased hypothesis and the predictability of the risk premium using the available market data. Section 7 concludes the paper.

\section{The Iberian Electricity Market}

The Iberian Electrical Energy Market (MIBEL) is a joint wholesale electricity market for Spain and Portugal. ${ }^{1}$ The wholesale electricity spot market allows the interaction between several types of buyers, such as reference retailers, re-sellers and direct consumers, and sellers (the electricity power producers). The spot market is managed and regulated by the Spanish division of the Iberian Energy Market Operator (OMIE). The spot market is composed by the daily and intra-day markets. The daily market sets the electricity prices for the twenty-four hours of the following day (the day-ahead). Prices and volumes are determined by the equilibrium between supply and demand for each hour of the dayahead (marginal pricing model). When the traded electricity exceeds the interconnection network capacity between Spain and Portugal, a market splitting mechanism sets in and different electricity prices take place in each country. The technical viability of the daily market schedule is guaranteed by the system operator. Adjustments to the final viable daily schedule are possible via the intra-day markets. Once the daily market closes, six intra-day markets sessions are held, on which market agents can adjust their positions up to four hours ahead of real time delivery.

\footnotetext{
${ }^{1}$ See the MIBEL website, http://www.mibel.com, for more information on its market structure.
} 
The Operador do Mercado Ibérico de Energia (OMIP) is responsible for organizing and managing the derivatives section of MIBEL. The derivatives traded in OMIP are futures, options, swaps and other forward contracts on electricity, and can have either physical or purely financial delivery. There are base-load and peak-load derivative products. The delivery period of base-load derivatives covers all daily hours, while peak-load derivatives only covers peak hours (typically from 8 a.m. to 7 p.m.).

The OMIClear performs the role of clearing house, central counter-party, and settlement system. Bilateral transactions can also be registered trough OMIClear. Two trading systems coexist within OMIP [20]: the continuous market and the call auction. The continuous trading is the default trading mode, in which anonymous buy and sell orders match immediately, according to the best pricing rule, generating trades with an undetermined number of prices in each trading session. In the call auction trading, a single-price auction maximizes the traded volume, with all trades being settled at the same price.

The underlying asset of all futures contracts is a notional supply/receiving of electric energy at a constant power of $1 \mathrm{MWh}$ during all hours of the delivery period. These contracts are quoted in euros per MWh and the available delivery periods are day, weekend, week, month, quarter and year. The delivery price is computed using a spot price reference index.

\section{Basic Theories on Futures Pricing and Risk Pre- mium}

Mainly, there are two pricing theories for the futures contracts on commodities: the costof-carry model [22] and the hedging pressure theory [23]. The latter is valid for both storable and non-storable commodities, while the former is only applicable for storable commodities. Below, we give a brief description of both theories. We follow [18], where the reader can find a detailed discussion.

Assuming the absence of storing costs and internal revenues from the underlying commodity, the cost-of-carry theory says that in equilibrium

$$
F_{t, T}=S_{t} e^{r \tau},
$$

where $F_{t, T}$ is the futures price at time $t$ for delivery at $T$, with $t<T$ (hence, the time to delivery is denoted by $\tau=T-t$ ), while $S_{t}$ is the value of the underlying commodity at time $t$, and $r$ is the time-independent risk-free rate.

Storage costs and convenience yields can be incorporated into the model as

$$
F_{t, T}=S_{t} e^{(r+q-c) \tau}
$$

where $q$ is the continuous rate of storage costs and $c$ is the continuous convenience yield. These equations are deduced from arbitrage-free arguments.

Because the cost-of-carry model is only applicable to storable commodities, only the hedging pressure theory is appropriate for pricing electricity futures. The theory is built 
on the fact that futures contracts are mainly hedging instruments, as they protect the investor against future price changes of the underlying asset. Therefore, the futures price reflects the expected price of the underlying asset at the delivery period plus a risk premium, which is the implicit cost associated with transferring the risk between market agents. Its sign depends on whether the hedgers are mainly buyers or sellers of the underlying commodity. Sellers with a more risk-averse posture than buyers are willing to accept a lower price for the futures, while buyers with a more risk-averse attitude than sellers are able to pay a higher price for the futures.

The risk premium may be defined ex-ante or ex-post: ${ }^{2}$

$$
\begin{gathered}
R P_{t, T}^{\text {ex-ante }}=\log \left(\mathrm{E}_{t}\left[S_{T}\right]\right)-\log \left(F_{t, T}\right), \text { or } \\
R P_{t, T}^{\text {ex-post }}=\log \left(\bar{S}_{T}\right)-\log \left(F_{t, T}\right),
\end{gathered}
$$

where the operator $\mathrm{E}_{t}[$.$] represents the conditional expectation at time (day) t$, and $\bar{S}_{T}$ denotes the realized spot price over the delivery time period $T$. Because the expected price is not directly observable, the ex-ante definition of risk premium requires a model for the dynamics of the underlying asset. Different models generally result in different estimates for the expected underlying asset price, and thus in distinct values for the exante risk premium. The ex-ante risk premium can be written as the ex-post risk premium plus a forecast error,

$$
R P_{t, T}^{\text {ex-ante }}=R P_{t, T}^{\text {ex-post }}+\left\{\log \left(\mathrm{E}_{t}\left[S_{T}\right]\right)-\log \left(\bar{S}_{T}\right)\right\} .
$$

The forecast error $\left\{\log \left(\mathrm{E}_{t}\left[S_{T}\right]\right)-\log \left(\bar{S}_{T}\right)\right\}$ is the difference between the expected and the realized price during the delivery period, and is generally assumed to be a white noise. Thus, the ex-post risk premium is a good proxy for the ex-ante risk premium, and evidence of a non-zero ex-post risk premium is also evidence of a non-zero ex-ante risk premium.

\section{Data description}

We use the daily spot and futures prices extracted from the OMIP webpage. The data covers the period from 1 July 2006 until 31 March 2017. Both spot and futures prices correspond to the Spanish zone of the Iberian Electricity Market. The spot reference price, which is also the price considered by OMIClear for computing the delivery price, is the daily SPEL base index, corresponding to the arithmetic mean of hourly marginal prices for the 24 hours of the day.

The futures prices correspond to the settlement prices, fixed by OMIP on a daily basis. We only consider the SPEL base-load futures contracts with monthly delivery. During the overall period were traded 128 of these futures contracts. The reason why we have chosen to work only with monthly SPEL base-load futures has to do with liquidity concerns. The Iberian electricity futures market is highly illiquid, with just a few contracts traded each day. The distribution of volume among contracts is the following: monthly delivery, $50 \%$, quarterly and yearly deliveries, $37 \%$ and $13 \%$, respectively.

\footnotetext{
${ }^{2}$ Throughout this paper, we define the risk premium as in [11].
} 
Figure 1 presents the distribution of number of trades per trading day until delivery. ${ }^{3}$ As expected, the average number of trades increases gradually as the contracts approximate the delivery period, however, liquidity is quite low, achieving an averaged maximum of only 2.5 trades per day.

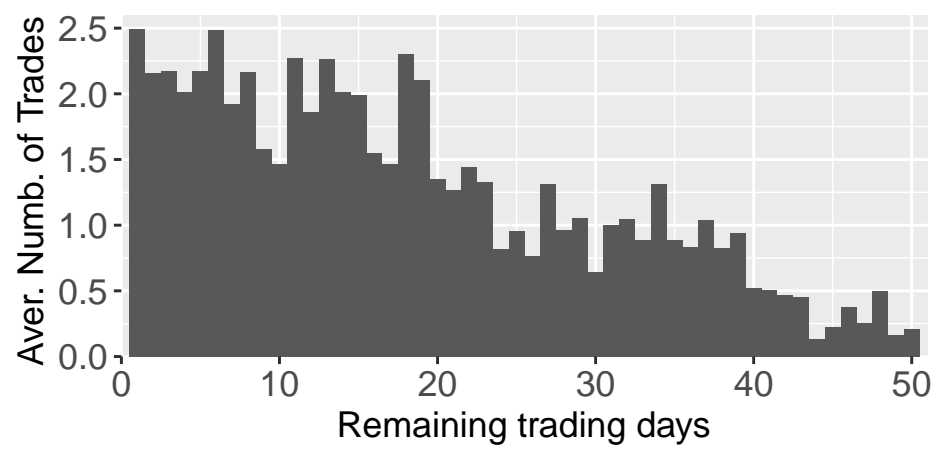

Figure 1: Average number of trades on monthly base-load futures contracts.

\section{Spot and futures price dynamics}

Fig. 2 shows the daily spot prices path for the overall sample. This series presents tempo-

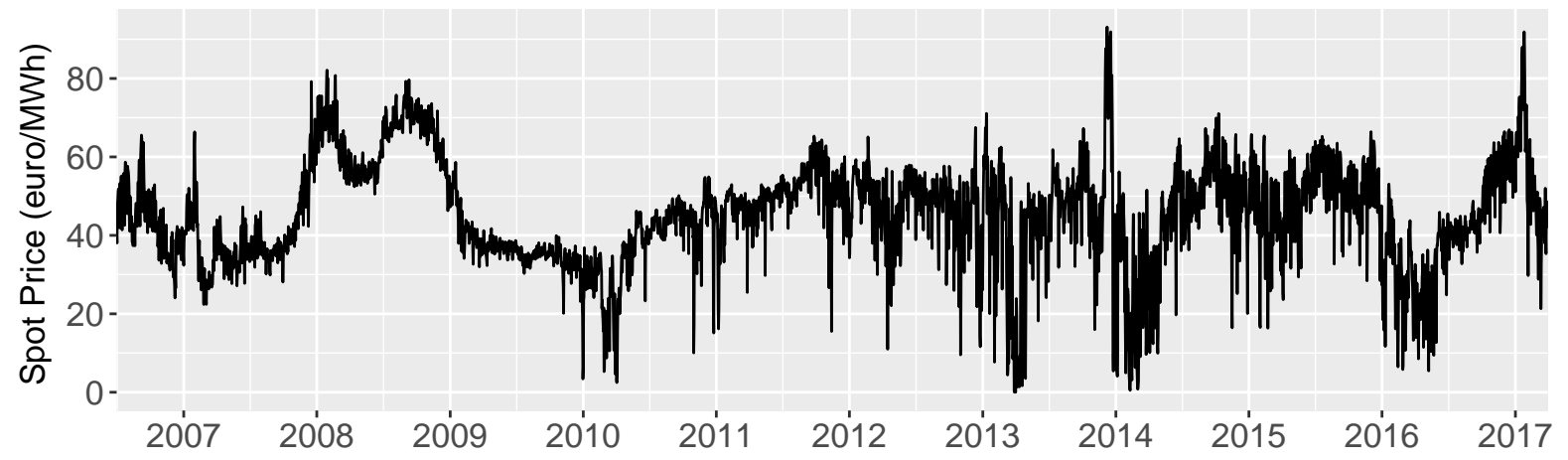

Figure 2: Daily day-ahead spot prices (in €/MWh) since 1 July 2006 until 31 March 2017.

rary spikes, frequent extreme values and high volatility clustering. The spikes correspond to periods of unanticipated high electricity demand, leading to extreme fluctuations on spot prices. Forecasting these jumps in the spot dynamics remains an important challenge in electricity markets. The high volatility clustering also results from the inability to smooth the supply and demand interrelationship via inventories [24]. The spot prices also seem to follow a mean-reversion process, i.e., it fluctuates around a long-term equilibrium value. All these features are typical of electricity markets, and are often attributed to the non-storable nature of electricity and to the reduced number of market players. Table 1 shows a statistical summary of spot prices.

\footnotetext{
${ }^{3}$ The numerical and graphical analysis presented in this work were performed in R and Gretl.
} 
Table 1: Descriptive statistics on daily spot prices.

\begin{tabular}{cc}
\hline \hline & Spot Price \\
\hline Maximum & 93.110 \\
Day & $2013-12-08$ \\
Minimum & 0.0000 \\
Days & $2013-04-01$ and $2014-03-29$ \\
Mean & 45.332 \\
Std. Dev. & 13.510 \\
Skewness & -0.2496 \\
Kurtosis & 3.8275 \\
ADF & -5.8262 \\
& $(<0.01)$ \\
PP & -433.92 \\
& $(<0.01)$ \\
\hline \hline
\end{tabular}

Note: The Augmented Dickey-Fuller (ADF) and Phillips-Perron (PP) test the null hypothesis of the presence of an unit root. The p-values of these statistics are in parentheses.

The sample mean is $45.332 € / \mathrm{MWh}$ and the standard deviation is $13.51 € / \mathrm{MWh}$. The highest spot price is $93.11 € / M W h$ (December 8, 2013), whilst electricity was sold for free on April 1, 2013, and on March 29, 2014. The negative skewness indicates more frequent downward spikes, whilst there is mild excess kurtosis. The Augmented Dickey-Fuller (ADF) and Phillips-Perron (PP) tests reject the null hypothesis of a unit root, and thus spot prices seem stationary.

Table 2 shows the spot price statistics yearly. The most striking result is in fact the instability of these statistics, with the yearly means ranging from $35.318 € / \mathrm{MWh}$ in 2016 , to $64.426 € / \mathrm{MWh}$ in 2008 , and the standard deviation ranging from $5.5831 € / \mathrm{MWh}$ in 2009 to $17.464 € / M W h$, a value more than three times higher, in 2013. Most of these years present negative skewness and excess kurtosis, but still there is no discernible pattern.

Table 2 also highlights some relevant economic events that happened during this period. Firstly, the financial crisis of 2009 affected several energy commodities prices (gas, oil, and coal) and also wholesale and retail electricity prices, worldwide. This also happened in the Iberian electricity market (MIBEL), where the average price decreased from $64.426 € / \mathrm{MWh}$, in 2008, to 36.962€/MWh, in 2009. In 2009, the electricity price reached a lowest value of $3.4 € / \mathrm{MWh}$, and remained low in 2010. In fact, due to the low demand and abundant renewable energy, the MIBEL prices went down to zero for several hours in both February and March of 2010 [25]. Secondly, the spot price variation in 2013 was remarkable: it was zero on April 1 and and 93.11€/MWh on December 8 (the highest value in the sample). In April 2013, an unprecedented power generation combination of high hydro-based and lower fossil fuel generation levels took place in the Iberian Peninsula. This exceptional combination of power generation sources led to several days in April with average prices between zero and 10€/MWh [26]. However, in December 2013, the wind and hydro-based power generation decreased, leading to a generation mix mainly composed by expensive conventional sources, which drove the price up to $93.11 € / \mathrm{MWh}$ 
Table 2: Descriptive statistics on spot prices yearly.

\begin{tabular}{ccccccc}
\hline \hline & 2006 & 2007 & 2008 & 2009 & 2010 & 2011 \\
\hline Maximum & 65.560 & 79.210 & 82.130 & 58.620 & 54.910 & 65.310 \\
Day & $09-07$ & $12-17$ & $01-29$ & $01-16$ & $12-11$ & $09-26$ \\
Minimum & 24.050 & 22.380 & 46.300 & 3.4000 & 2.4700 & 15.520 \\
Day & $12-08$ & $02-25$ & $12-25$ & $12-31$ & $04-03$ & $11-13$ \\
Mean & 44.280 & 39.346 & 64.426 & 36.962 & 37.011 & 49.922 \\
Std. Dev. & 8.3340 & 8.858 & 7.1905 & 5.5831 & 10.633 & 6.9245 \\
Skewness & 0.1851 & 1.2423 & -0.0690 & 0.4559 & -1.0723 & -1.1616 \\
Kurtosis & 0.1851 & 4.9228 & 2.1997 & 9.0005 & 3.7924 & 7.4789 \\
\hline \hline & & & & & & \\
\hline \hline & 2012 & 2013 & 2014 & 2015 & 2016 & 2017 \\
\hline Maximum & 67.510 & 93.110 & 71.060 & 66.410 & 59.650 & 91.880 \\
Day & $12-12$ & $12-08$ & $10-10$ & $12-02$ & $10-20$ & $01-25$ \\
Minimum & 9.5500 & 0.0000 & 0.4800 & 16.350 & 5.4600 & 21.310 \\
Day & $11-01$ & $04-01$ & $02-09$ & $02-22$ & $05-08$ & $03-12$ \\
Mean & 47.237 & 44.257 & 42.130 & 50.324 & 35.318 & 55.596 \\
Std. Dev. & 8.8362 & 17.464 & 15.657 & 9.2580 & 10.912 & 14.621 \\
Skewness & -1.3597 & -0.4343 & -0.8609 & -0.8428 & -0.5416 & 0.4672 \\
Kurtosis & 5.5484 & 4.0608 & 3.1127 & 3.8368 & 3.1020 & 2.8726 \\
\hline \hline
\end{tabular}

Note: The first and last years are incomplete. The sample comprises the period from 1 July 2006 until 31 March 2017.

$[27]$.

Weather conditions strongly affects household electricity demand, which tends to produce low frequency seasonalities; while economic and business activities generate seasonalities on distinct time scales: intra-daily, weekly and monthly. For instance, business electricity demand is higher during the day (at business hours) than at night and is lower on weekends than on business days. The electricity supply tends also to present seasonalities, for instance, it depends on water reservoirs levels, which, in turn, depend mostly on weather conditions. Because we are going to deal with monthly futures, we are interest in study just low frequency seasonalities. Figure 3 show the average price and volatility by month, while Table 3 presents some descriptive statistics by season of the year.

The lowest and highest average spot prices are observed in April and September, respectively, while the volatility has lowest values in May and June and highest values in January and February. The most interesting results presented in Table 3 is the low average price in the Spring and the high price volatility in the Winter.

In order to analyze the futures price dynamics we define three time series corresponding to 1-month ahead, 2-month ahead and 3-month ahead futures contracts. Figure 4 show these series and also the spot price. From a visual inspection, all three futures series seem to follow a similar pattern and are more jagged as delivery is nearer. 


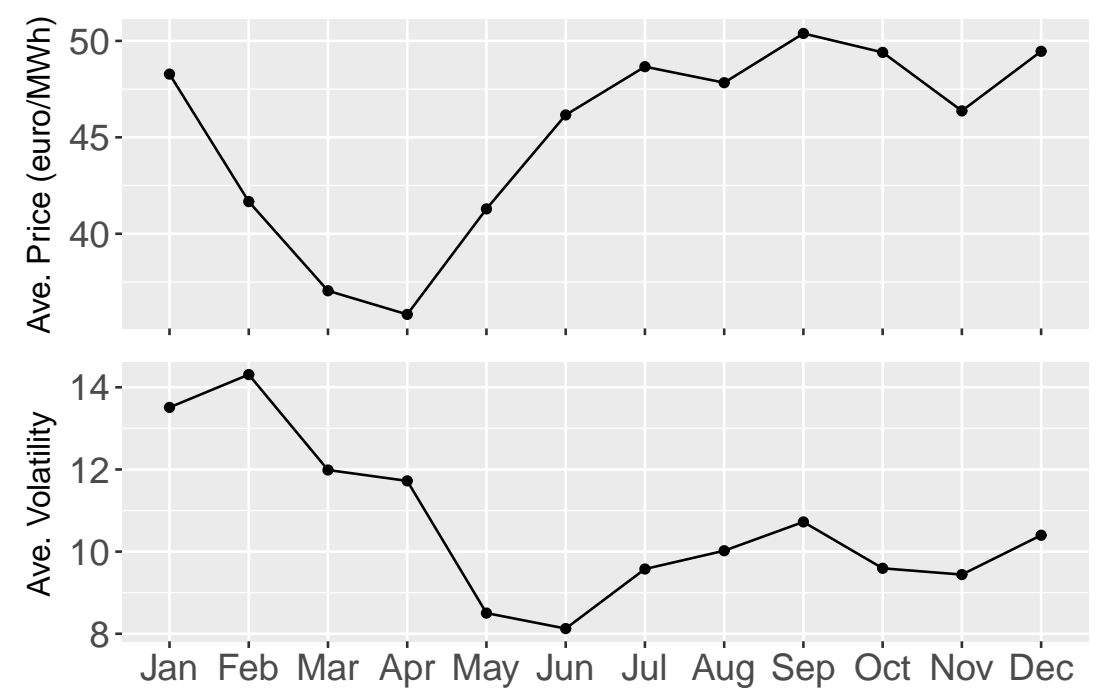

Figure 3: Monthly average spot prices (top) and volatility (bottom).

Table 3: Descriptive statistics on daily spot prices per season of the year.

\begin{tabular}{ccccc}
\hline \hline & Fall & Spring & Summer & Winter \\
\hline Maximum & 79.650 & 66.730 & 75.860 & 93.110 \\
Minimum & 9.5500 & 0.0000 & 18.180 & 0.4800 \\
Mean & 48.727 & 38.041 & 47.610 & 46.639 \\
Std. Dev. & 11.413 & 13.222 & 9.9786 & 15.990 \\
Skewness & 0.1681 & -0.6530 & 0.3754 & -0.1575 \\
Kurtosis & 2.8765 & 3.2486 & 2.7595 & 3.3184 \\
\hline \hline
\end{tabular}

The comparison between the descriptive statistics of both futures and spot prices (see also Table 1) allows us to verify that the spot market is more volatile than the futures market, and that the volatility decreases with time to delivery. This last result is in accordance with the Samuelson effect (for a study of this issue in electricity futures see [28]). Both skewness and kurtosis increase with the time to delivery, showing that the futures prices distribution becomes more positive asymmetrical and leptokurtic. The Augmented Dickey-Fuller (ADF) and Phillips-Perron (PP) tests show that all series tend to be stationary.

\section{The risk premium}

Herein, we analyze the ex-post risk premium of the SPEL base-load futures contracts for monthly delivery, designate hereafter simply as risk premium and computed according to Eq. (4), where the numerator is given by the realized average spot price over the corresponding futures delivery month and the denominator is given by the futures settlement price at the last trading day before delivery:

$$
R P_{T-1, T}=\log \left(\bar{S}_{T}\right)-\log \left(F_{T-1, T}\right)
$$




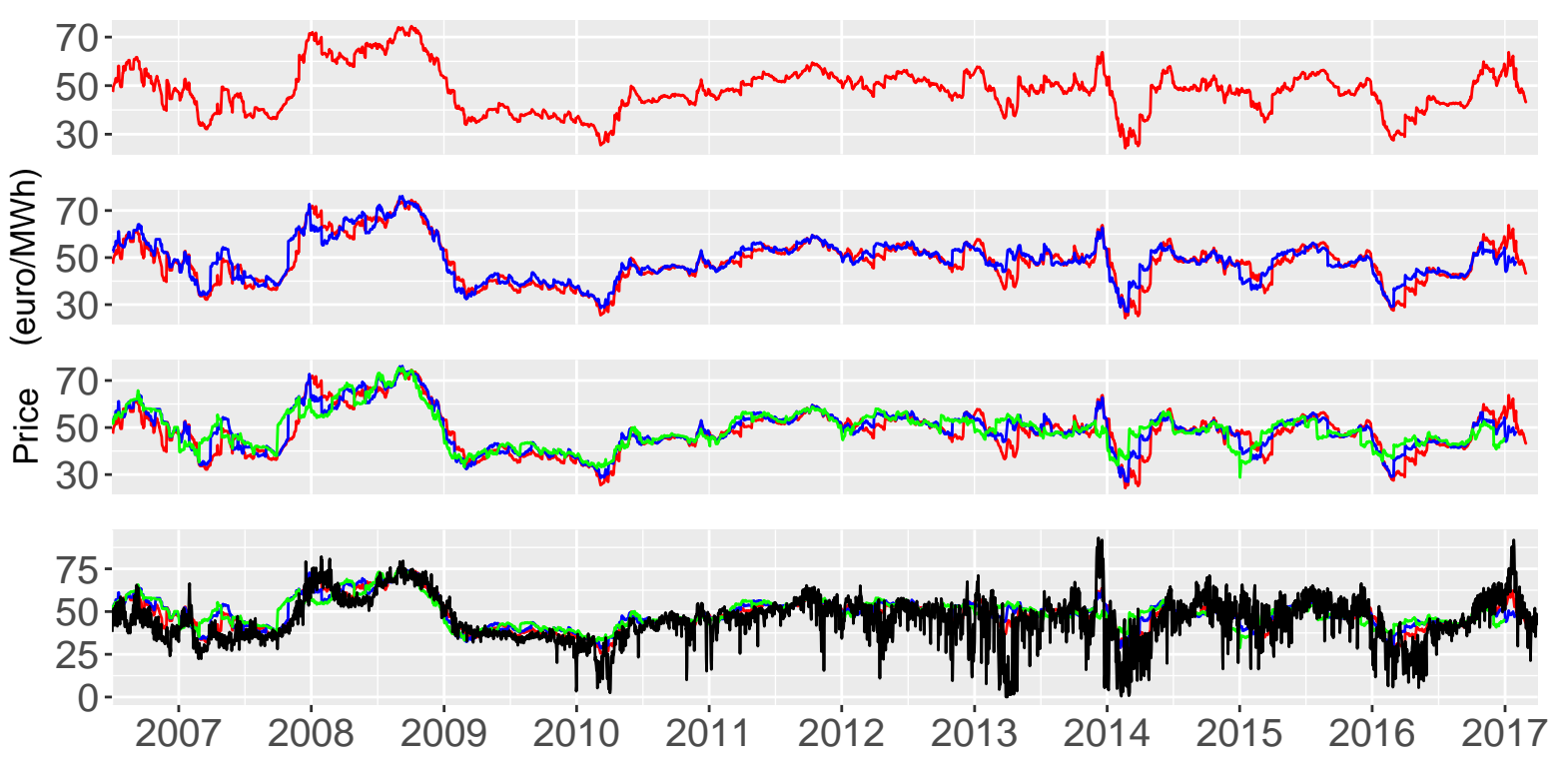

Figure 4: Futures prices for the 1-month ahead (red), the 2-month ahead (blue), and the 3 -month ahead (green) contracts. The spot prices (black) are also shown on the bottom panel.

Table 4: Descriptive statistics on the 1-month ahead, the 2-month ahead and the 3-month ahead futures prices.

\begin{tabular}{cccc}
\hline \hline & 1-month ahead & 2-month ahead & 3-month ahead \\
\hline Maximum & 74.500 & 76.130 & 75.380 \\
Day & $2008-10-03$ & $2008-09-08$ & $2008-08-29$ \\
Minimum & 24.250 & 26.880 & 28.750 \\
Day & $2014-02-20$ & $2014-02-27$ & $2015-01-02$ \\
Mean & 48.126 & 48.899 & 49.040 \\
Std. Dev. & 9.2491 & 8.7025 & 7.9154 \\
Skewness & 0.2337 & 0.3530 & 0.5759 \\
Kurtosis & 3.1637 & 3.3056 & 3.5642 \\
ADF & -3.5661 & -3.5971 & -3.2595 \\
& $(0.0359)$ & $(0.0329)$ & $(0.0776)$ \\
PP & -24.777 & -24.032 & -22.702 \\
& $(0.0252)$ & $(0.0309)$ & $(0.0411)$ \\
\hline \hline
\end{tabular}

Note: The Augmented Dickey-Fuller (ADF) and Phillips-Perron (PP) test the null hypothesis of the presence of an unit root. The p-values of these statistics are in parentheses.

\subsection{Risk premium dynamics}

The time series of the risk premium (in percentage) is displayed in Fig. 5, and its descriptive statistics are presented in Table 5. The dataset contains 128 monthly futures contracts. 


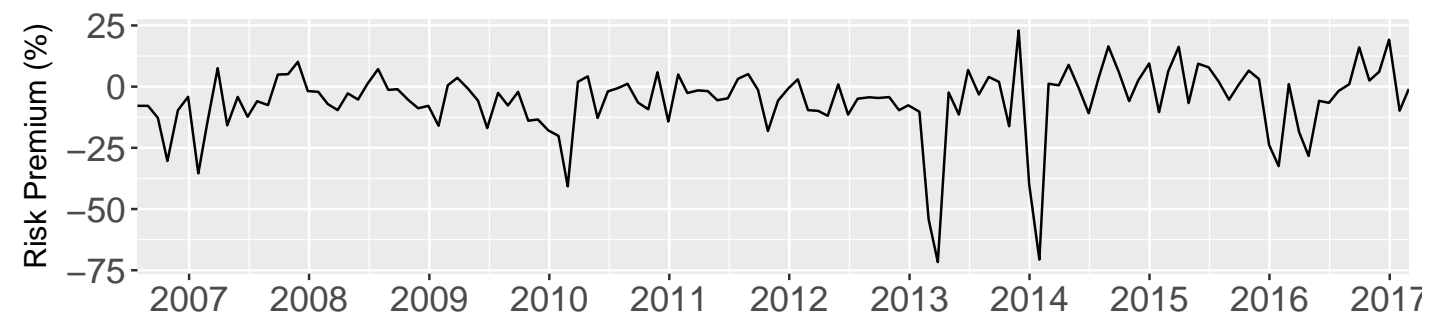

Figure 5: The risk premium (\%) time series.

The minimum and maximum risk premiums occurred in April 2013 and December 2013, respectively, as the result of the particular events already documented in Section 5. So it seems that the futures market didn't anticipated these events. The risk premium is negative most of the time $(66.41 \%)$ with a mean and median values of $-5.77 \%$ and $-4.17 \%$, respectively. This negative risk premium indicates that market agents are willing to pay a higher futures price in order to reduce their risk exposure to electricity price increases. The risk premium is quite volatile and the skewness and kurtosis indicate that there are frequent jumps, specially negative ones (see Fig. 5). The first order correlation is 0.2810 , which denotes some persistence in the risk premium. According to the ADF and PP tests, the risk premium series is stationary.

Table 5: Descriptive statistics on the risk premium.

\begin{tabular}{cc}
\hline \hline & Risk Premium (\%) \\
\hline No. Obs & 128 \\
\% negative & 66.406 \\
Maximum & 22.929 \\
Contract & Dec-13 \\
Minimum & -71.676 \\
Contract & Apr-13 \\
Median & -4.1721 \\
Mean & -5.7736 \\
Std. Dev. & 14.182 \\
Skewness & -2.0239 \\
Kurtosis & 9.7174 \\
$\rho(1)$ & 0.2810 \\
ADF & -4.2863 \\
& $(<0.01)$ \\
PP & -140.63 \\
& $(<0.01)$ \\
\hline \hline
\end{tabular}

Note: $\rho(1)$ denotes the first order autocorrelation. The Augmented Dickey-Fuller (ADF) and Phillips-Perron (PP) test the null hypothesis of the presence of an unit root. The p-values of these statistics are in parentheses.

It is also interesting to analyze the risk premium by season of the year. Some statistical information can be seen in Table 6. On average, the Winter futures were traded $-12.4 \%$ higher, whilst Summer futures were traded just $-2.1 \%$ higher, than the respective 
realized spot prices. The risk premium volatility is highest in the Winter and lowest in the Summer. Hence, the lowest risk premium level and volatility reflect the higher predictability of the risk premium during the Summer.

Table 6: Descriptive statistics on the risk premium (\%) per season of the year.

\begin{tabular}{ccccc}
\hline \hline & Fall & Spring & Summer & Winter \\
\hline Maximum & 22.929 & 16.272 & 16.465 & 19.203 \\
Minimum & -30.367 & -71.676 & -16.920 & -70.674 \\
Mean & -2.5607 & -5.9800 & -2.0603 & -12.400 \\
Std. Dev. & 10.431 & 15.330 & 6.9453 & 18.972 \\
Skewness & -0.1095 & -2.6711 & 0.3033 & -1.2325 \\
Kurtosis & 3.6532 & 12.485 & 3.2364 & 4.4604 \\
\hline \hline
\end{tabular}

An issue usually addressed in these type of studies is the term structure of the level and volatility of the risk premium. Hence, we also compute the average risk premium and its volatility over all contracts as a function of the days until delivery, i.e., the risk premium at each day is averaged over all contracts. Additionally, we also present the term structure of the correlation between the futures and spot prices and the futures volatility, as functions of the time to delivery. The definition of the time variable is not trivial, as different results are obtained whether the total number of days or only the number of trading days (business days) until delivery is considered. A striking result is apparent from the visualization of Fig. 6: the inclusion of weekends, when, in fact, the futures market is closed, results into spurious features. The level and the volatility of the risk premium present jumps at regular intervals, which would imply a seasonal pattern and introduces an underestimation error into the risk premium volatility and an overestimation error in the correlation between the spot and the futures prices.

The risk premium level and volatility depend non-linearly on the trading days to delivery, which can be closely modeled by a square root process in time to delivery, i.e. on $\tau=T-t$, the remaining trading days, with $\tau=1$ representing the last trading day. ${ }^{4}$ Likewise, the correlation between the realized spot average and the futures prices can also be modelled by a square root in time to delivery. The OLS estimates, all significant at the $1 \%$ level, are the following:

$$
\begin{aligned}
\text { Average } R P_{\tau, T} & =-5.3108-0.7697 \sqrt{\tau}, \quad R^{2}=0.9721 ; \\
\text { Volatility } R P_{\tau, T} & =13.411+1.5568 \sqrt{\tau}, \quad R^{2}=0.9698 ; \\
\operatorname{Corr}\left(\bar{S}_{T}, F_{\tau, T}\right) & =0.9533-0.0558 \sqrt{\tau}, \quad R^{2}=0.9772 .
\end{aligned}
$$

The futures prices volatility displays a linear dependence on $\tau$ (remaining trading days),

$$
\text { Volatility } F_{\tau, T}=9.6590-0.0299 \tau, \quad R^{2}=0.9479
$$

where the estimated values are also significant at the $1 \%$ level.

\footnotetext{
${ }^{4} \mathrm{As}$ in [7], we also regressed the risk premium level on the number and squared number of trading days until delivery, with slightly less robust outcomes.
} 

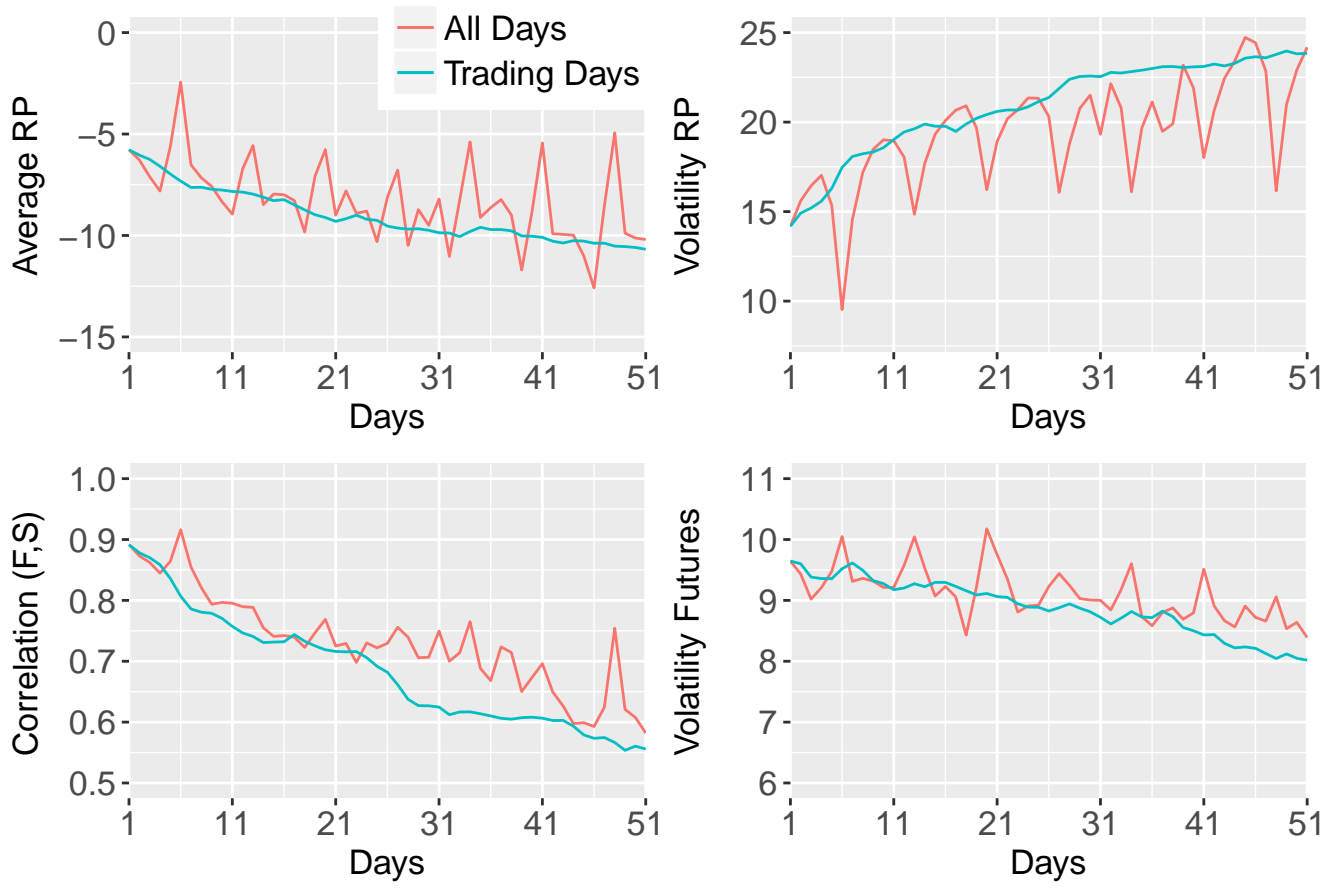

Figure 6: Top panel: term structure of the level and volatility of the risk premium (\%). Bottom panel: correlation between the realized spot and the futures prices, and futures prices volatility.

The risk premium decreases, in absolute value, as the futures contract approach the last trading day, meaning that the futures prices are noisier as they are away from the delivery month, and therefore the futures' last trading day is quite particular regarding its informativeness about the next month spot price average. The risk premium computed as $\log \left(S_{T}\right)-\log \left(\bar{F}_{[1,30], T}\right)$, where $\bar{F}_{[1,30], T}$ is the average of the futures settlement prices over the last 30 trading days before delivery, has a lower mean value of $-7.777 \%$ and its volatility increases to 18.014. These results are quite logical, implying that, as time passes, market players have more information on the near month spot price and therefore they review their expectations improving the properties of the futures price as a predictor of the future spot price. The risk premium volatility decreases as the delivery month approaches. This is because the futures volatility increases when delivery approaches (once again giving some evidence on the existence of the Samuelson effect) but so does the correlation between the futures and spot prices, at a higher rate.

\subsection{Unbiased Forward Hypothesis and Risk Premium Predictabil- ity}

If markets are informationally efficient, the futures prices are unbiased predictors of the future spot prices and therefore there is no systematic risk premium.

A simple way to test the weak-form Efficient Market Hypothesis is via the following equation [29]:

$$
\bar{S}_{T}=\alpha+\beta F_{t, T}+\epsilon_{T} .
$$


The futures prices are unbiased forecasts of future spot prices if $\alpha=0$ and $\beta=1$. In other words, $\alpha$ significantly different from zero indicates the presence of systematic risk premium, and $\beta$ significantly different from one shows evidence of biased predictions, and thus of a forecast error.

The linear regression Eq. (7) is estimated measuring the futures price at the last trading day, $F_{T-1, T}$, and as the averaged price in the last 10 trading days, $\bar{F}_{[1,10], T}$. Table 7 presents the results.

Table 7: Tests on the unbiased forward hypothesis

\begin{tabular}{lcccc}
\hline \hline & $F_{T-1, T}$ & $F_{T-1, T}$ & $F_{T-1, T}$ & $\bar{F}_{[1,10], T}$ \\
& OLS & OLS $(-3$ lower obs. $)$ & Robust & Robust \\
\hline$\alpha$ & -4.7992 & -2.7424 & -2.4562 & -2.0774 \\
& $(0.0181)$ & $(0.1440)$ & $(0.2085)$ & $(0.4187)$ \\
$\beta$ & 1.0585 & 1.0233 & 1.0161 & 0.9982 \\
& $(0.0000)$ & $(0.0000)$ & $(0.0000)$ & $(0.0000)$ \\
$H_{0}: \beta=1$ & $(0.1383)$ & $(0.5482)$ & $(0.6896)$ & $(0.9734)$ \\
$R^{2}$ & 0.7951 & 0.8218 & 0.8674 & 0.793 \\
$Q(10)$ & 11.473 & 8.339 & 13.07 & 14.842 \\
\multirow{2}{*}{$Q^{2}(10)$} & $(0.3219)$ & $(0.5958)$ & $(0.2198)$ & $(0.1379)$ \\
& 50.176 & 12.047 & 50.314 & 61.878 \\
& $(0.0000)$ & $(0.2819)$ & $(0.0000)$ & $(0.0000)$ \\
\hline \hline
\end{tabular}

Note: $F_{T-1, T}$ and $\bar{F}_{[1,10], T}$ designate the futures price at the last trading day and as the averaged price in the last 10 trading days, respectively. Equation (7) was estimated for $F_{T-1, T}$ using OLS on all the data and on the data without the three lower extreme values (OLS (- 3 lower obs.)), and finally by the Tukey's biweight robust estimator. This estimator was also used for $\bar{F}_{[1,10], T}$. The p-values are presented in parentheses, resulting from the Newey-West heteroscedasticityautocorrelation robust standard errors, with a bandwidth equal to 3 (Bartlett kernel). The line $H_{0}: \beta=1$ presents the p-values on the null hypothesis of no bias in the forecast. The table also presents the Ljung-Box statistics on the null hypothesis of no autocorrelation in residuals, $Q(10)$, and squared residuals, $Q^{2}(10)$, for 10 lags.

Although the mainstream of the literature provides empirical evidence against this hypothesis in the electricity futures markets, we are not able to reject this hypothesis for the Iberian electricity market. Using OLS, the intercept, for the $F_{T-1, T}$ regression, is statistically different from zero at the $5 \%$ level, however this inference is biased given the existence of autocorrelation in the squared residuals. In fact, if we withdraw just the three more influential negative extreme values from the series, the significance of $\alpha$ disappears and the same happens to the autocorrelation in the squared residuals. Facing heteroscedastic errors and the presence of highly influential observations, we carried out robust estimations on all the data. The results show that $\alpha$ is not statistically different from zero and $\beta$ is not statistically different from one, although the estimates of $\beta=1.0161$ for $F_{T-1, T}$ and $\beta=0.9982$ for $\bar{F}_{[1,10], T}$ indicate that the futures market slightly overestimates the future spot price in the last trading day whilst underestimates it, on average, during the last 10 trading days before delivery. 
The weak-form of the Efficient Market Hypothesis generaly suggests that asset prices incorporate all the available historical information, and therefore are unpredictable in terms of any past information. In the present framework, this translates into the impossibility of predicting the risk premium using all the available historical information on spot prices and futures prices or any combination of both. The obvious candidate to test the risk premium predictability, as suggested by [19], is the futures prices. ${ }^{5}$ To test if the futures prices have some predictive power on the risk premium, we conjecture that, as the delivery date approaches, market agents revise their predictions on the risk premium, however, even at the last trading day, their predictions are not perfect. Accordingly, the sequence of futures prices until the last trading day provide information about the risk premium, $R P_{T-1, T}$. Basically, this is in accordance with [30], that argue that a sequence of prices may be more informative than the last known price. This conjecture, may be tested using the following linear regression:

$$
R P_{T-1, T}=\alpha+\beta f_{\tau, T}+\epsilon_{T},
$$

where $f_{\tau, T}$ is the daily logarithmic futures return, such that $\tau=T-t$, with $t<T$. Therefore

$$
f_{\tau, T}=\log \left(F_{T-\tau, T}\right)-\log \left(F_{T-\tau-1, T}\right) .
$$

The results are presented in Table 8 using the futures price information up to 11 trading days before the beginning of the delivery month.

Table 8: Regressions of the risk premium on the daily futures returns

\begin{tabular}{cccccc}
\hline \hline & $\alpha$ & $p$-value & $\beta$ & $p$-value & $R^{2}$ \\
\hline$f_{1, T}$ & -0.0512 & 0.0005 & 2.4626 & 0.0407 & 0.1090 \\
$f_{2, T}$ & -0.0565 & 0.0003 & 0.5687 & 0.8859 & 0.0054 \\
$f_{3, T}$ & -0.0533 & 0.0007 & 1.2813 & 0.0689 & 0.0215 \\
$f_{4, T}$ & -0.0468 & 0.0004 & 2.9088 & 0.0006 & 0.1225 \\
$f_{5, T}$ & -0.0480 & 0.0003 & 2.7611 & 0.0000 & 0.2061 \\
$f_{6, T}$ & -0.0514 & 0.0006 & 2.0179 & 0.0040 & 0.0802 \\
$f_{7, T}$ & -0.0578 & 0.0002 & 0.5272 & 0.3343 & 0.0041 \\
$f_{8, T}$ & -0.0576 & 0.0002 & 0.1660 & 0.7610 & 0.0004 \\
$f_{9, T}$ & -0.0575 & 0.0002 & 0.6878 & 0.2563 & 0.0079 \\
$f_{10, T}$ & -0.0571 & 0.0001 & 0.9055 & 0.2022 & 0.0166 \\
\hline \hline
\end{tabular}

Note: Equation (8) was estimated using OLS. The p-values are presented in parentheses, resulting from the Newey-West heteroscedasticity-autocorrelation robust standard errors, with a bandwidth equal to 3 (Bartlett kernel).

In these regressions, $\alpha$ has always a significant negative value, while $\beta$ is always positive, but it is only significant, at the $1 \%$ level, for the futures returns on 4,5 and 6 days prior to delivery.

We can go further and check if futures prices provide additional information after controlling for the explanatory variables proposed by the most used equilibrium model

\footnotetext{
${ }^{5}$ We have also applied the testing procedure to the spot returns and to the futures basis with quite inferior results.
} 
for electricity markets. According to[1], the electricity futures premium depends on the market expectations on the variance and asymmetry of the spot price at delivery. Given the definition of the risk premium used here, its relationship with the variance and asymmetry should be positive and negative, respectively. Usually, this model is tested ex-post, i.e., using the realized values for the variance and asymmetry of the spot price at delivery. Taking all this into consideration, we propose the following model:

$$
R P_{T-1, T}=\alpha+\beta f_{[3,7], T}+\vartheta V\left[S_{T}\right]+\gamma A\left[S_{T}\right]+\varepsilon_{T},
$$

where $f_{[3,7], T}$ is the futures return from day 7 until day 3 , prior to delivery, i.e., $f_{[3,7], T}=$ $\log \left(F_{T-3, T}\right)-\log \left(F_{T-7, T}\right)$, and $V\left[S_{T}\right]$ and $A\left[S_{T}\right]$ are the realized variance and nonstandardised asymmetry (third central moment) of the daily spot prices in month $T$. We also estimate two restricted versions of this model, superimposing $\vartheta=\gamma=0$ and $\beta=0$. The estimation results presented in Table 9 show that the volatility and asymme-

Table 9: On the predictive power of future returns

\begin{tabular}{lccc}
\hline \hline & Model 1 & Model 2 & Model 3 \\
\hline$\alpha$ & -0.0349 & -0.0044 & 0.0077 \\
& $(0.0021)$ & $(0.7217)$ & $(0.4896)$ \\
$f_{[3,7], T}$ & 1.6499 & - & 1.3759 \\
& $(0.0000)$ & & $(0.0000)$ \\
$V\left[S_{T}\right]$ & - & -0.1494 & -0.1304 \\
& & $(0.0000)$ & $(0.0000)$ \\
$A\left[S_{T}\right]$ & - & -0.7312 & -0.6423 \\
& & $(0.0000)$ & $(0.0000)$ \\
$R^{2}$ & 0.2859 & 0.3644 & 0.5576 \\
\hline \hline
\end{tabular}

Note: Equation (10) was estimated via OLS. The p-values are in parentheses, resulting from the Newey-West heteroscedasticity-autocorrelation robust standard errors, with a bandwidth equal to 3 (Bartlett kernel). The variance and the asymmetry variables were multiplied by $10^{-2}$ and $10^{-4}$, respectively

try coefficients are significant at the $1 \%$ level, however the coefficient on the volatility has a negative sign, which grasps some doubts on the applicability of the model proposed by [1] to this dataset. The unrestricted model (Model 3) has a $R^{2}$ above $55 \%$, implying that more than one half of the risk premium variability is explained by the futures returns and the ex-post variance and asymmetry of the spot price at delivery. The futures returns, solely, explains more than $28 \%$ of the risk premium variability (Model 1), and even, after controlling for the variance and asymmetry in the spot price, the futures returns are still significant at the $1 \%$ level.

To give additional evidence on the previous claim, we design the following speculative trading strategy: firstly, let us consider that at time $T-2$ the trader estimates the risk premium signal for month $T$ using the price sequence from 7 to 3 days prior to delivery for that contract and previous contracts in the sample, that is, he uses recursively Model 1. Then he trades futures at time $T-1$ according to the expected signal (if the sign is positive (negative) he takes a long (short) position in the futures contract). The results 
of the comparison of this strategy with the unconditional strategy, assuming that the risk premium is always negative and therefore the trader always short the futures contract, is shown in Table 10.

Table 10: Comparison between two simple trading strategies

\begin{tabular}{lcc}
\hline \hline & Futures-based & Unconditional \\
\hline No. of successes & 83 & 80 \\
Freq. of successes & $64.84 \%$ & $62.50 \%$ \\
Mean return & $6.29 \%$ & $5.45 \%$ \\
Std. Dev. of returns & 0.1386 & 0.1421 \\
Sharpe ratio & 0.4539 & 0.3835 \\
\hline \hline
\end{tabular}

Note: The futures-based strategy uses Model 1 of Table 9 to extract recursively the signal of the risk premium. The first estimation uses just 5 contracts, and therefore the statistics are obtained for 123 contracts. The unconditional strategy is designed upon the assumption that the risk premium is always negative. The Sharpe ratio is given by the division between the mean and standard deviation of the strategies' returns series.

The futures-based strategy obtains more 3 successes than the unconditional strategy, resulting in an increase in the mean return and, surprisingly, a decrease in the returns' standard deviation. Therefore the futures-based strategy has a Sharpe ratio roughly $18 \%$ above the corresponding metric for the unconditional strategy.

The number of observations is rather small, but nevertheless gathering information on the futures market near delivery seems a quite valuable idea.

\section{Conclusions}

This work provides an empirical analysis on the spot and futures prices (base-load monthly contracts) formed on the Iberian Electrical Energy Market, using up-to-date data.

Some features, typical of electricity markets, attributed to the non-storable nature of electricity and to the reduced number of market players are also found here. Namely, we document the presence temporary spikes, frequent extreme values, high volatility clustering and low frequency seasonalities. The spot volatility is higher than the futures volatility, which increases with the time to maturity. This gives some supportive evidence on the existence of the Samuelson effect in this market.

The ex-post risk premium, computed as the logarithm of the ratio between the spot price at delivery and the futures price in the last trading day, is $-5.77 \%$ on average, but shows a high level of variability. We also show that the risk premium is an increasing non-linear function of the trading days until delivery.

Although we were not able to reject the unbiased forward hypothesis, we found a significant relationship between the risk premium and the futures returns. These two results seem contradicting, however we must stress that the first result is drawn upon observations of a single point in the futures price process for each contract, while the second result derives from the observations of the price path near the maturity. In sum, 
despite the small sample (only 128 contracts), the illiquidity of the futures market (on average no more than 2.5 trades per day) and our exclusive focusing on the financial aspects of the market (without any consideration on the fundamentals), our main result is the claim that the sequence of futures prices, near delivery, has valuable information for predicting the risk premium in the Iberian electricity market.

\section{References}

[1] Hendrik Bessembinder and Michael L Lemmon. Equilibrium pricing and optimal hedging in electricity forward markets. Journal of Finance, 57(3):1347-1382, 2002.

[2] Alvaro Cartea and Marcelo G Figueroa. Pricing in electricity markets: a mean reverting jump diffusion model with seasonality. Applied Mathematical Finance, 12(4):313-335, 2005.

[3] Álvaro Cartea and Pablo Villaplana. Spot price modeling and the valuation of electricity forward contracts: The role of demand and capacity. Journal of Banking \& Finance, 32(12):2502-2519, 2008.

[4] Craig Pirrong and Martin Jermakyan. The price of power: The valuation of power and weather derivatives. Journal of Banking \& Finance, 32(12):2520-2529, 2008.

[5] Hany A Shawky, Achla Marathe, and Christopher L Barrett. A first look at the empirical relation between spot and futures electricity prices in the United States. Journal of Futures Markets, 23(10):931, 2003.

[6] Fred Espen Benth, Álvaro Cartea, and Rüdiger Kiesel. Pricing forward contracts in power markets by the certainty equivalence principle: explaining the sign of the market risk premium. Journal of Banking \& Finance, 32(10):2006-2021, 2008.

[7] Matthäus Pietz. Risk premia in the German electricity futures market. In Energy and Environment, 2009. ICEE 2009. 3rd International Conference on, pages 160170. IEEE, 2009.

[8] Christian Redl, Reinhard Haas, Claus Huber, and Bernhard Böhm. Price formation in electricity forward markets and the relevance of systematic forecast errors. Energy Economics, 31(3):356-364, 2009.

[9] Julio J Lucia and Hipòlit Torró. On the risk premium in Nordic electricity futures prices. International Review of Economics \& Finance, 20(4):750-763, 2011.

[10] Audun Botterud, Tarjei Kristiansen, and Marija D Ilic. The relationship between spot and futures prices in the Nord Pool electricity market. Energy Economics, 32(5):967-978, 2010.

[11] Rafał Weron and Michał Zator. Revisiting the relationship between spot and futures prices in the Nord Pool electricity market. Energy Economics, 44:178-190, 2014. 
[12] Goknur Umutlu, André Dorsman, and Erdinc Telatar. The Electricity Market, DayAhead Market and Futures Market, pages 109-128. Springer Berlin Heidelberg, Berlin, Heidelberg, 2011.

[13] Christian Redl and Derek W Bunn. Determinants of the premium in forward contracts. Journal of Regulatory Economics, 43(1):90-111, 2013.

[14] Derek W Bunn and Dipeng Chen. The forward premium in electricity futures. Journal of Empirical Finance, 23:173-186, 2013.

[15] Fred Espen Benth, Richard Biegler-König, and Rüdiger Kiesel. An empirical study of the information premium on electricity markets. Energy Economics, 36:55-77, 2013.

[16] Stein-Erik Fleten, Liv Aune Hagen, Maria Tandberg Nygård, Ragnhild SmithSivertsen, and Johan M Sollie. The overnight risk premium in electricity forward contracts. Energy Economics, 49:293-300, 2015.

[17] Paolo Falbo, Daniele Felletti, Silvana Stefani, et al. Electricity Futures. World Scientific Book Chapters, pages 545-565, 2015.

[18] Alvaro Cartea and Pablo Villaplana. An analysis of the main determinants of electricity forward prices and forward risk premia. In Quantitative Energy Finance, pages 215-236. Springer, 2014.

[19] Jose María Ballester, Francisco Climent, and Dolores Furió. Market efficiency and price discovery relationships between spot, futures and forward prices: the case of the Iberian Electricity Market (MIBEL). Spanish Journal of Finance and Accounting/Revista Española de Financiación y Contabilidad, 45(2):135-153, 2016.

[20] Álvaro Capitán Herráiz and Carlos Rodríguez Monroy. Analysis of the efficiency of the Iberian power futures market. Energy Policy, 37(9):3566-3579, 2009.

[21] Dolores Furió and Vicente Meneu. Expectations and forward risk premium in the Spanish deregulated power market. Energy Policy, 38(2):784-793, 2010.

[22] Nicholas Kaldor. Speculation and economic stability. Review of Economic Studies, 7(1):1-27, 1939.

[23] John Maynard Keynes. A treatise on money: The applied theory of money, volume 2. AMS Press, 1930.

[24] Helen Higgs and Andrew Worthington. Stochastic price modeling of high volatility, mean-reverting, spike-prone commodities: The Australian wholesale spot electricity market. Energy Economics, 30(6):3172-3185, 2008.

[25] Quarterly report on european electricity markets. Market Observatory for Energy, 3(1), 2010.

[26] DG Energy. Quarterly report on european electricity markets. Market Observatory for Energy, 6(2), 2013. 
[27] DG Energy. Quarterly report on european electricity markets. Market Observatory for Energy, 6(3 and 4), 2013.

[28] Edouard Jaeck and Delphine Lautier. Volatility in electricity derivative markets: The Samuelson effect revisited. Energy Economics, 59:300-313, 2016.

[29] Erik Haugom and Carl J Ullrich. Market efficiency and risk premia in short-term forward prices. Energy Economics, 34(6):1931-1941, 2012.

[30] David P Brown and Robert H Jennings. On technical analysis. Review of Financial Studies, 2(4):527-551, 1989. 
CeBer Working Papers

(Available on-line at www.uc.pt/go/ceber)

\begin{tabular}{|c|c|}
\hline $18-02$ & $\begin{array}{l}\text { The Iberian electricity market: Price dynamics and risk premium in an illiquid market - } \\
\text { Márcio Ferreira \& Hélder Sebastião }\end{array}$ \\
\hline 2018-01 & $\begin{array}{l}\text { Health Investment and Long run Macroeconomic Performance: a quantile regression } \\
\text { approach - Francisca Silva, Marta Simões \& João Sousa Andrade }\end{array}$ \\
\hline $2017-12$ & $\begin{array}{l}\text { Deflation in the Euro Zone: Overview and Empirical Analysis - Pedro Bação \& António } \\
\text { Portugal Duarte }\end{array}$ \\
\hline $2017-11$ & $\begin{array}{l}\text { Fiscal Consolidation Programs and Income Inequality - Pedro Brinca, Miguel H. Ferreira, } \\
\text { Francesco Franco, Hans A. Holter \& Laurence Malafry }\end{array}$ \\
\hline $2017-10$ & $\begin{array}{l}\text { The interconnections between Renewable Energy, Economic Development and } \\
\text { Environmental Pollution. A simultaneous equation system approach - Elias Soukiazis, } \\
\text { Sara Proença \& Pedro André Cerqueira }\end{array}$ \\
\hline 2017-09 & $\begin{array}{l}\text { The Renminbi: A Warrior for Competitiveness? - Pedro Bação, António Portugal Duarte } \\
\& \text { Matheus Santos }\end{array}$ \\
\hline $2017-08$ & Le Portugal et l'Euro - João Sousa Andrade \\
\hline $2017-07$ & $\begin{array}{l}\text { The Effect of Public Debt on Growth in Multiple Regimes in the Presence of Long-Memory } \\
\text { and Non-Stationary Debt Series - Irina Syssoyeva-Masson \& João Sousa Andrade }\end{array}$ \\
\hline $2017-06$ & $\begin{array}{l}\text { The Blank and the Null: An examination of non-conventional voting choices - Rodrigo } \\
\text { Martins }\end{array}$ \\
\hline $2017-05$ & $\begin{array}{l}\text { Where is the information on USD/Bitcoins hourly price movements? - Helder Sebastião, } \\
\text { António Portugal Duarte \& Gabriel Guerreiro }\end{array}$ \\
\hline 2017-04 & $\begin{array}{l}\text { The response of non-price competitiveness and productivity due to changes in passed } \\
\text { income gaps. Evidence from the OECD countries - Pedro André Cerqueira, Micaela } \\
\text { Antunes \& Elias Soukiazis }\end{array}$ \\
\hline $2017-03$ & $\begin{array}{l}\text { Dutch Disease in Central and Eastern European Countries - João Sousa Andrade \& } \\
\text { António Portugal Duarte }\end{array}$ \\
\hline 2017-02 & $\begin{array}{l}\text { On the gains of using high frequency data and higher moments in Portfolio Selection- Rui } \\
\text { Pedro Brito, Hélder Sebastião \& Pedro Godinho }\end{array}$ \\
\hline 2017-01 & $\begin{array}{l}\text { Growth adjustments through non-price competitiveness and productivity. A cumulative } \\
\text { causation approach- Elias Soukiazis, Micaela Antunes \& Pedro André Cerqueira }\end{array}$ \\
\hline
\end{tabular}


A série CeBER Working Papers foi iniciada em 2017. 